\title{
Study of Serum Malondialdehyde, Paraoxonase and Lipid Profile in Pregnancy with Pre-Eclampsia and Normal Pregnancy
}

\author{
Dr. Ch. VenkataRamana, M.D., \\ Associate Professor Of Biochemistry, Guntur Medical Ciollege, Guntur. A.P., India.
}

\begin{abstract}
Introduction:Normal pregnancy is a state of physiological stress in which there is increased production of free radicals and increased lipid peroxidation towards the end of pregnancy and in parallel, total antioxidant capacity gradually increases leading to an oxidative balance maintained throughout the pregnancy but in pre-eclampsia there is a biochemical imbalance with increase in lipid peroxidation and deficient antioxidant defenses.
\end{abstract}

Aim Of Study: The present study is undertaken to estimate serum levels of MDA, PARAOXONASE, Total Cholesterol, LDL-C, HDL-C, Triglycerides in normal pregnant women and pregnant women with Preeclampsia and to evaluate the correlation between MDA and PARAOXONASE and to evaluate MDA as a marker of Lipid Peroxidation.

Materials And Methods: A case control study was done including 50 pregnant women with Pre-eclampsia as cases and 50 age matched normal pregnant women as controls. Serum lipid profile was estimated and serum MDA level was estimated by (NADIGER et al method), PARAOXONASE was estimated by (MACKNESS AND MACKNESS method).

Results: TC, LDL-C, TG and MDA levels were significantly increased and HDL-C and PARAOXONASE levels were significantly decreased in cases compared to controls. Pearson's correlation analysis showed a significant negative correlation between serum levels of MDA and PARAOXONASE and a significant positive correlation between serum levels of PARAOXONASE and HDL-C and significant negative correlation between serum levels of PARAOXONASE and LDL-C in cases.

Summary And Conclusion: In PRE-ECLAMPSIA there is altered lipid metabolism with increased lipid perosidation and decreased antioxidants. $L D L$ is more susceptible to oxidation, it redily gets oxidized by MDA, to form oxidized LDL which is taken up by macrophages via scavenger receptors and form FOAM cells which in turn results in atherogenesis. $O x-L D L$ particles might be involved in vascular endothelial damage. Hence it may be concluded that endothelial cell damage and dysfunction as the major cause of PRE-ECLAMPSIA.

Key Words: MDA:Malondialdehyde, Tc: Total Cholesterol

TG:Triglycerides,

HDL-C:High Density Lipoprotein Cholesterol,

VLDL-C:Very Low Density Lipoprotein Cholesterol,

LDL-C:Low Density Lipoprotein Cholesterol.

\section{Introduction}

Pregnancy is a state of physiological stress in which many physiological and metabolic functions are altered to considerable extent in the milieu interior of the body laying more and more stress on the biochemical changes which becomes exaggerated in complications of pregnancy like pre-eclampsia ${ }^{1}$.

pre-eclampsia; a multisystem disorder and a clinical condition in pregnancy characterized by blood pressure of $\geq 140 / 90 \mathrm{mmHg}$ noted for the first time during pregnancy on $\geq 2$ occasions at least 6 or more hours apart, after 20 weeks of gestation with proteinuria of $\geq 300 \mathrm{mg} / 24$ hours or $\geq+1$ by dipstick method in a random urine sample ${ }^{2}$.

The etiology of pre-eclampsia is multifactorial. Information from published studies points to the placenta as the probable pathogenic focus of pre-eclampsia as the disease usually resolves within 24-48 hours after delivery of the placenta.

Although the precise involvement of the placenta in pre-eclampsia remains unclear, there are indications that the trophoblastic invasion of the uterine spiral arteries is abnormal in women who develop preeclampsia, this impaired invasion leads to decreased placental perfusion and ultimately placental hypoxia and placental oxidative stress ${ }^{3}$.

Oxidative stress is probably one of the mechanisms involved in vascular endothelial dysfunction ${ }^{1}$. During hypoxia high amounts of free radicals are formed that induce lipid peroxidation of polyunsaturated fatty acids in cell membrane producing malondialadehyde (MDA) as one of the end product which reflects the 
oxidative status of the biological system ${ }^{3}$. Pre-eclampsia is an endothelial disease associated with major involvement of lipid mediated oxidative damage and reduced antioxidant status ${ }^{4}$.

A consistent positive association between maternal dyslipdaemia and the risk of developing preeclampsiaalready been found. MDA an end product of lipid peroxidation causes oxidation of LDL molecules. The oxidized LDL is taken up by macrophages via scavenger receptors and form foams cells, this in turn results in atherogenesis.

Paraoxonase an esterase enzyme associated with HDL exerts a protective effect against oxidative damage of circulating lipoproteins. The hydrolysis of the oxidized phospholipids by Paraoxonase destroys the biologically active lipids in mildly oxidized LDL, thereby HDL and its associated enzyme interrupts a process that would otherwise lead to oxidative damage. Paraoxonase thus can be an indicator of antioxidant status in pre-eclampsia ${ }^{4}$.

\section{Materials And Methods}

A cross sectional study of serum lipid profile, serum levels of MDA as a marker of lipid peroxidation and serum level of PARAOXONASE as antioxidant was conducted in normal pregnant women as controls and pregnant women with pre-eclampsia as cases, admitted in Govt. General Hospital, Guntur from 01.01.2013 to 31.03.2014.

A) Subjects:

Based on inclusion and exclusion criteria a total number of 100 subjects (50 cases and 50 age matched controls) were selected for the present study.

Inclusion criteria:

a) 50 proven cases of pre-eclampsia in the age group 20-45 years on the basis of definition given by National High Blood Pressure Education Programme (NHBPEP 2000).

Pregnant women of $\geq 20$ weeks of gestation with blood pressure of $\geq 140 / 90 \mathrm{mmHg}$ noted for the first time during pregnancy on $\geq 2$ occasions at least 6 or more hours apart with proteinuria of $\geq 1+(\geq 300 \mathrm{mg} / \mathrm{dl}) \mathrm{by}$ dipstick method in a random urine sample.

b) 50 age matched normal pregnant women in the age group of 20-45 years with $\geq 20$ weeks of gestation without any major an illness and who are not on any medications.

Exclusion criteria: Pregnant women

- With chronic hypertension that was present before pregnancy

- Who are diabetic and on insulin therapy

- Who are taking any antihypertensive or anyhypolipidemic drugs

- Who are on antioxidant medication

- With proven liver or cardiac or renal disease or any other major illness

- With gestational diabetes

- With multiple pregnancy

- With abruptio placenta/hydatidiform mole/molar pregnancy

\section{B) Collection Of Blood Sample:}

After 12 hours of overnight fasting about $5 \mathrm{ml}$ of venous blood was drawn from the subjects including both cases and controls under aseptic precautions in a sterile plain bulb and allowed to clot. The serum was separated by centrifugation and used estimation of MDA, Paraoxonase and lipid profile.

\section{Parameters Measured: \\ 1. Malondialdehyde (MDA) \\ 2. Paraoxonase \\ 3. Total Cholesterol (TC) \\ 4. Triglycerides (TG) \\ 5. HDL-Cholesterol (HDL-C) \\ 6. LDL-Cholesterol (LDL-C)}

Serum MDA was estimated by NADIGER et al method ${ }^{14}$. Principle: Auto-oxidation of unsaturated fatty acids lead to the formation of semi stable peroxides which then undergoes a series of reactions to form short chain aldehydes like malondialdehyde (MDA). One molecule of MDA reacts with two molecules of thiobarbituric acid (TBA) with elimination of two molecules of water to yield pale pink coloured solution, the absorption of which is measured at $630 \mathrm{~nm}$. 
Serum PARAOXONASE was estimated by MACKNESS AND MACKNESS method ${ }^{15}$ PRINCIPLE: Paraoxonase activity was determined using p-nitrophenyl acetate as a substrate. The increase in the absorbance at $412 \mathrm{~nm}$ due to formation of p-nitrophenol was measured.

Total serum cholesterol was estimated by ZLATKS, ZAK and BOYLE method. HDL-C was assessed by phosphotungstate-Magnesium chloride precipitation method. (ref. BURSTEIN, M. SCHOLNICK, H.R. AND MPRFIN 1970). Serum triglycerides were estimated by Acetyl acetone method. VLDL-C was calculated by using Friedewalds formula.

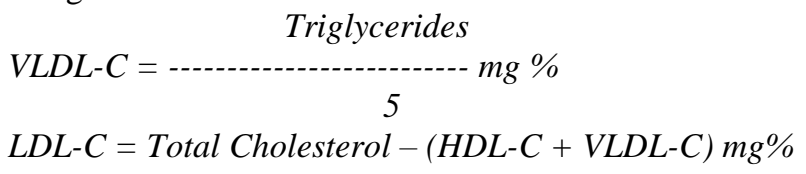

\section{Figures And Tables}

Table 1

\begin{tabular}{|c|c|c|c|c|c|c|}
\hline & & \multirow{2}{*}{$\begin{array}{l}\text { Controls } \\
(n=50)\end{array}$} & \multirow{2}{*}{$\begin{array}{l}\text { Cases } \\
(n=50)\end{array}$} & \multicolumn{3}{|c|}{ Controls V/s Cases } \\
\hline & & & & Mean diff & $\begin{array}{c}\mathrm{t} \\
\text { Vale }\end{array}$ & $\begin{array}{c}\mathbf{p} \\
\text { value }\end{array}$ \\
\hline \multirow[t]{2}{*}{ TC mg/dl } & Mean \pm SD & $189.7 \pm 20.3$ & $229.2 \pm 22.4$ & 39.5 & 9.25 & $<0.001 * *$ \\
\hline & Range & $127.3-225.0$ & $199.0-290.0$ & & & \\
\hline \multirow[t]{2}{*}{ LDL-C mg/dl } & Mean \pm SD & $123.5 \pm 17.8$ & $156.5 \pm 23.2$ & 33.0 & 8.00 & $<0.001 * *$ \\
\hline & Range & $68.0-157.0$ & $124.0-217.9$ & & & \\
\hline \multirow[t]{2}{*}{ HDL-C mg/dl } & Mean \pm SD & $36.36 \pm 5.20$ & $32.43 \pm 5.76$ & 3.93 & 3.58 & $<0.05^{*}$ \\
\hline & Range & $28.0-53.0$ & $23.5-53.0$ & & & \\
\hline \multirow[t]{2}{*}{ TG mg/dl } & Mean \pm SD & $160 \pm 26$ & $202.1 \pm 22.3$ & 41.4 & 8.54 & $<0.001 * *$ \\
\hline & Range & $99.0-213$ & $135.0-266.8$ & & & \\
\hline
\end{tabular}

Unpaired t test

$*$ p value $<0.05$ (significant)

$* *$ p value $<0.001$ (highly significant)

Table 2

\begin{tabular}{|c|c|c|c|c|c|c|}
\hline & & \multirow{2}{*}{$\begin{array}{l}\text { Controls } \\
(n=50)\end{array}$} & \multirow{2}{*}{$\begin{array}{l}\text { Cases } \\
(n=50)\end{array}$} & \multicolumn{3}{|c|}{ Controls V/s Cases } \\
\hline & & & & Mean diff & $\begin{array}{c}\mathrm{t} \\
\text { Vale }\end{array}$ & $\underset{\text { value }}{\mathbf{p}}$ \\
\hline \multirow[t]{2}{*}{ MDA nmol/ml } & Mean \pm SD & $2.53 \pm 0.90$ & $7.22 \pm 1.53$ & 4.69 & 18.66 & $<0.001 * *$ \\
\hline & Range & $1.20-4.50$ & $4.47-10.40$ & & & \\
\hline \multirow[t]{2}{*}{ Paraoxonasenmol/ml/min } & Mean \pm SD & $91.98 \pm 12.88$ & $58.52 \pm 9.25$ & 33.47 & 14.92 & $<0.001 * *$ \\
\hline & Range & $65.4-113.52$ & $43.8-75.6$ & & & \\
\hline
\end{tabular}

Unpaired t test

$*$ p value $<0.05$ (significant)

$* * \mathrm{p}$ value $<0.001$ (highly significant)

Table 3

\begin{tabular}{|l|c|c|}
\hline \multicolumn{1}{|c|}{ Correlation } & r value & p value \\
\hline MDA vsParaoxonase & -0.64 & $<0.001^{* *}$ \\
\hline Paraoxonasevs HDL-C & +0.41 & $<0.05^{*}$ \\
\hline Paraoxonasevs LDL-C & -0.29 & $<0.05^{*}$ \\
\hline
\end{tabular}

r Pearson's correlation coefficient

$*$ p value $<0.05$ (significant)

$* * \mathrm{p}$ value $<0.001$ (highly significant) 


\section{Figure-1}

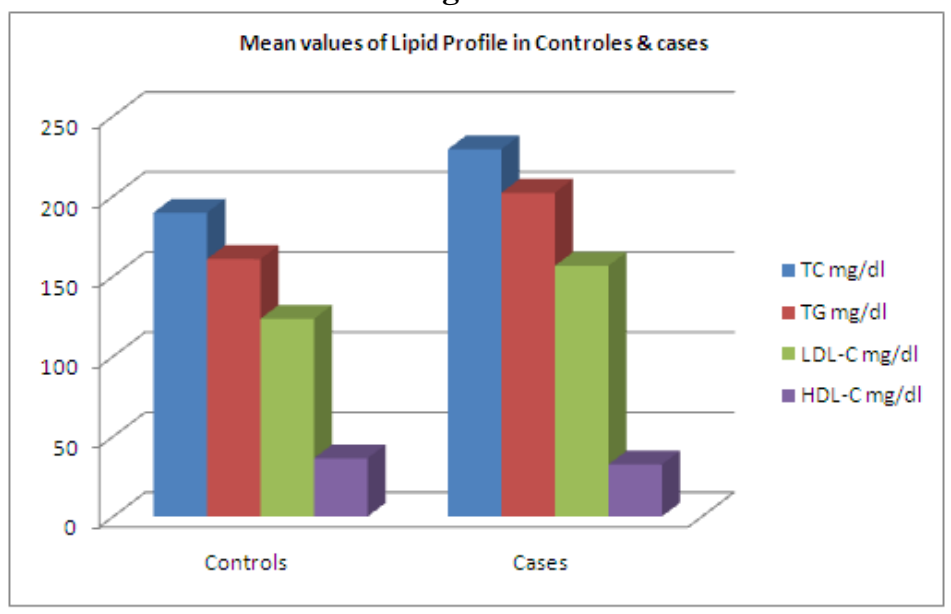

Figure -2

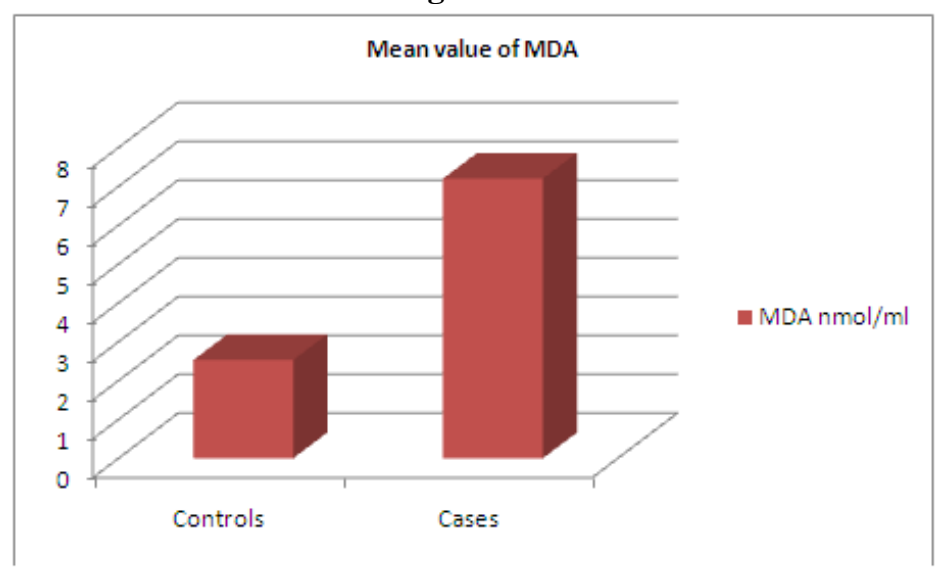

Figure - 3

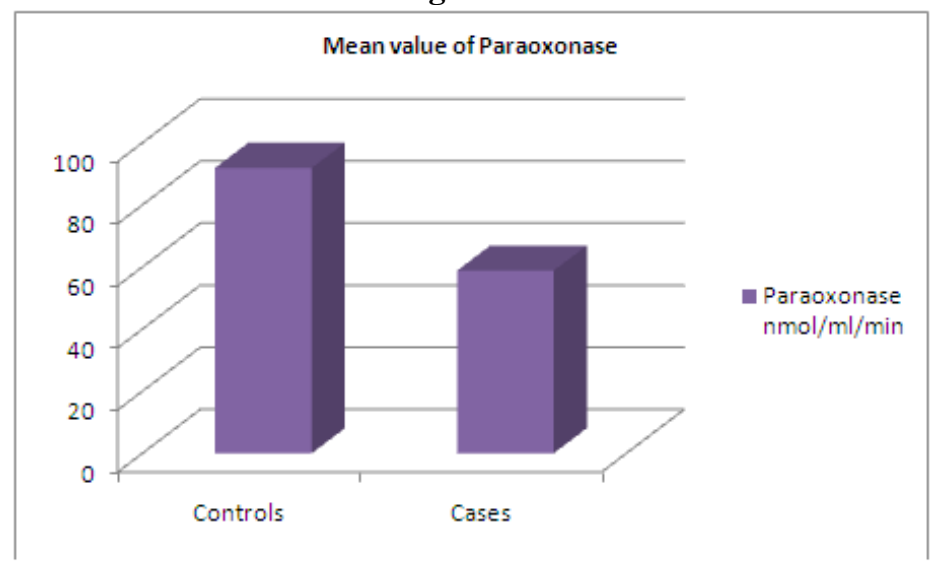

IV. Discussion:

Pre-eclampsia is the most important disease and a specific syndrome of pregnancy. Pre-eclampsia is associated with hyperlipidemia which may lead to its pathologensis as there is consistent positive association seen between hyperlipidemia and Pre-eclampsia. The increased free radicals and lipid peroxide causes peroxidation of lipids to produce MDA as its end product. LDL gets oxidized by MDA to form oxidized $\mathrm{LDL}^{5}$.

The characteristic Pre-eclampticulteroplacental lesion is similar to atherosclerotic lesion, display vessel wall necrosis and accumulation of lipid laden for Paraoxonase in the protection of LDL from oxidative modifications and prevents atherogenesis ${ }^{16}$. 


\section{Malondialdehyde (MDA):}

In the present study, serum levels of MDA are significantly increased $(\mathrm{p}<0.001)$ in pregnant women with pre-eclampsia as cases compared to normal pregnant women as controls. Serum levels of MDA are negatively correlated with paraoxonase levels. Excessive lipid peroxidation occurring in pre-eclampsia can be attributed to hypercholesterolemia and elevated levels of MDA which were found to be associated with elevated serum lipid levels indicating that pre-eclampsia is associated with excessive lipid peroxidation ${ }^{9}$. MDA plays a major role in LDL modification leading to formation of oxidized LDL. Oxidized LDL is taken up by macrophages via scavenger receptors and forms cells, this in turn results in atherogenesis ${ }^{5}$.

\section{Paraoxonase:}

In the present study the serum levels of Paraoxonase are significantly decreased $(\mathrm{p}<0.001)$ in pregnant women with pre-eclampsia as cases compared to normal pregnant women as controls. Serum levels Paraoxonase is positively correlated with serum levels of HDL-C and negatively correlated with serum MDA and LDL-C levels. The decrease in Paraoxonase activity in Pre-eclampsia is due to altered synthesis or secretion of HDL as the damaged liver cells are not able to express Paraoxonase; this is supported by the elevated serum transminase levels in pre-eclamptic women suggesting liver damage in these patients. Estrogen is known to inhibit the susceptibility opf oxidation of LDL and HDL. This function of estrogen is found to be mediated by HDL associated Paraoxonase enzyme which acts as an antioxidant. Estrogen is known to favorably affect lipid metabolites by reducing number of LDL-Cholesterol particles while increasing HDL-Cholesterol particles in plasma that are resistant to oxidation. Hence HDL bound Paraoxonase may participate in the above mentioned effects of estrogen. The decrease in estrogen in Pre-eclampsia possibly increases the susceptibility of LDL to oxidation through lowered HDL bound Paraoxonase in pre-eclamptic women; hence reduction in the activities of Paraoxonase in the present study and their relationship to HDL suggest that decrease in the Paraoxonase enzyme may play a role in pathogenesis of pre-eclampsia through predisposition to lipid peroxidation and increased susceptibility to oxidation of $\mathrm{LDL}^{3}$.

\section{Total Cholesterol (TC):}

In the present study serum levels of total Cholesterol are significantly increased $(p<0.001)$ in pregnant women with Pre-eclampsia as cases compared to normal pregnant women as controls. Increased serum levels of total cholesterol is due to insulin resistance; as it is found to be associated with increased cholesterol synthesis and due to reduced levels of HDL cholesterol as reverse transport of cholesterol to liver is impaired leading to its reduced excretion and increased serum ;levels of total cholesterol ${ }^{8}$.

\section{Triglycerides (TG):}

In the present study, serum levels of triglycerides are significantly increased $(\mathrm{p}<0.001)$ in pregnant women with Pre-eclampsia as cases compared to normal pregnant women as controls. The cause for increased serum triglyceride concentration could be due to increase in the hepatic lipase activity and decease in lipoprotein lipase activity. The increase in hepatic lipase activity is responsible for the increased synthesis of the TG in liver, whereas the decreased activity of lipoprotein lipase is responsible for the decreased catabolism of TG at the tissue level. Uptake of the remnant by the liver is found to be delayed leading to increased serum TG concentration. Increase in triglyceride increases the activity of cholesterol ester transfer protein which causes HDL to become enriched with triglycerides and VLDL with cholesterol. The VLDL enriched with cholesterol causes increased formation of more atherogenic variant of LDL particle known as small dense LDL ${ }^{12}$.

\section{HDL Cholesterol (HDL-C):}

In the present study, serum levels of HDL-C are significantly decreased $(\mathrm{p}<0.05)$ in pregnant women with Pre-eclampsia as cases compared to normal pregnant women as controls. Serum levels of HDL-C are positively correlated with serum Paraoxonase levels. Hypertriglyceridemia is the major cause of reduction in HDL-C concentration in these patients. Through CETP mediated exchange with TG rich VLDL particles, HDL particles become TG rich. Such TG rich HDL is rapidly catabolized by hepatic lipase, thus reducing its concentration $^{6,12}$.

\section{LDL Cholesterol (LDL-C):}

In the present study, serum levels of LDL-C are significantly increased $(\mathrm{p}<0.01)$ in pregnant women with Pre-eclampsia as cases compared to normal pregnant women as controls. Serum levels of LDL-C are negatively correlated with serum Paraoxonase levels. Increased cholesterol production, reduced HDL-C concentration, reduced HDL mediated reverse cholesterol transport are the reason for elevated LDL-C concentration $^{6}$. 


\section{Conclusion}

The present study suggest that dyslipidemia mediated activation of the endothelial cells by the placentally derived endothelial disturbing factors like lipid peroxides and trophoblastic components with a combination of oxidized lipoproteins could be regarded as possible contributors in the pathogenesis of Preeclampsia. Thus the assessment of serum lipids may be useful in prevention of development of Pre-eclampsia.

It can be concluded that in Pre-eclampsia, serum antioxidants are excessively utilized to counteract the cellular damage mediated by free radicals. Hence deficient antioxidants as well as increased lipid peroxidation may be important factors in the pathogenesis of Pre-eclampsia.

\section{References}

[1]. KashinakuntiSv, HkSunitha, Gurupadappa K Et Al, Lipid Peroxidation And Antioxidant Status In Pre-Eclampsia. Al Ameen J Med Sci 2010; 3(1): 38-4.

[2]. Dutta Dc, Hypertension In Pregnancy. In Dutta Dc. Text Book Of Obstetrics. $6^{\text {th }}$ Edition. Calcutta; New Central Book Agency (P) Ltd., 2004.221-242.

[3]. Kumru S. Aydin S, Ferit M Et Al, Changes Of Serum Paraoxonase (An Hdl-C Associated Lipophilic Antioxidant) And Arylesterase Activities In Severe Pre-Eclamptic Women. European Journal Of Obstetrics And Gynecology And Reproductive Biology 2004; 114:117-181.

[4]. Singh Hj. Pre-Eclampsia: Is It All In The Placenta? Malaysian Journal Of Medical Scinces 2009; 16(1) : 7-15.

[5]. Meera Ks, Maitra S, Hemalatha R. Increased Level Of Lipid Peroxidation In Pre-Eclampsia Pregnancy; A Relationship With Paraoxonase 1 Activity. Biomedical Research 2010; 21(4): 393-396.

[6]. Packard C. Tricylglycerol-Rich Lipoproteins And The Generation Of Small Dense Low-Density Lipoprotein. Biochemical Society Transactions 2003; 31(5): 1066-1069.

[7]. Tani M, Kawakami A, Mizuno Y Et Al. Small Dense Ldl Enhances Thp-1 Macrophage Foam Cell Formation. J Atherosclerosis And Thrombosis, 2011; 18:698-704.

[8]. Pihlajamaki J, Gylling H, Miettinen T, Laakso M. Insulin Resistance Is Associated With Increased Cholesterol Synthesis And Decreased Cholesterol Absorption In Normoglycemic Men. Journal Of Lipid Research 2004, 45:507-512.

[9]. Adiga U, D’souza V, Kamath A, Nandini. Antioxidant Activity And Lipid Preoxidation In Preeclampsia. J Chin Med Assoc 2007; 70(10); 435-438.

[10]. AksoyAn, Ozturkn, Aksoy H, Akcay F. Paraoxonase And Arylesterase Activities In Patients With Preeclampsia. The Eurasian Journal Of Medicine 2008: 40: 10-13.

[11]. Wakatsuki A, Ikenoue N, Okatani Y Et Al, Lipoprotein Particles In Pre-Eclampsia: Susceptibility To Oxidative Modification. Obstetrics And Gynecology 200; 96(1): 55-59.

[12]. E Pedro, Soca M, Ojeda Ls, Toro IcDyslipidemis In Pre-Eclampsia Syndrome. Corsalud 2013; 5(2); $221-225$.

[13]. Yoshida H, Kisugi R. Mechanisms OfLdl Oxidation ClinicaActa 2010; 411: 1875-1882.

[14]. Nadiger Ha, Marcus Sr, ChandrakalaMv, Kulkarni Dd. Malondialdehyde Levels In Different Organs Of Rats Subjected To Acute Alcohol Toxicity. Indian Journal Of Clinical Biochemistry 1986; 133-136.

[15]. MiMackness, D Harty, D Bhatnagar Et Al. Serum Paraoxonase Activity In Familial Hypercholesterolemia And Insulin Dependent Diabetes Mellitus. Atherosclerosis 1991; 86:193-199.

[16]. Demir B, Demir S, Atmaer Y Et Al. Serum Levels Of Lipids, Lipoproteins And Paraoxonase Activity In Pre-Eclampsia. The Journal Of International Medical Research 2011; 39: 1427-1431.

[17]. Siddiquila, Jaleel A, Tamini W Et Al, Role Of Oxidative Stress In The Pathogenesis Of Pre-Eclampsia. Arch GynecolObstet 2010; 282: 469-474. 